\title{
Proceedings of the 11th national conference on anticoagulant therapy
}

Preface

\author{
David A. Garcia
}

Published online: 3 March 2011

(C) Springer Science+Business Media, LLC 2011

The 11th National Conference on Anticoagulant Therapy sponsored by the Anticoagulation Forum was held in Boston, MA on May 5-7, 2011. The AC Forum continues to enjoy a committed and enthusiastic membership with participation in this year's meeting of over 800 attendees. The AC Forum's conference provides a unique opportunity to network and learn among professional colleagues with expertise in the diagnosis and treatment of thrombotic disorders. The 3 day conference included an outstanding roster of international expert speakers, whose presentations are published in these proceedings. As in the past, members had an opportunity to present abstracts of original research and case reports. Over 75 abstracts were presented and are reprinted in this supplement.

The Anticoagulation Forum, now celebrating its 20th anniversary, was founded by Dr. Jack Ansell in response to the need for a professional group to focus on the discipline of anticoagulation management and related therapies. The AC Forum is a multidisciplinary nonprofit organization that works to improve the quality of care for patients taking antithrombotic medications. The goals of the AC Forum are to provide education and networking opportunities for health care professionals, to promote the clinical application of evidence-based practices, to facilitate research aimed at improving health outcomes, and to inform healthcare policy, regulatory agencies, and industry about best practices. Its membership is made up predominantly of physicians, nurses, and pharmacists. The AC Forum has over 5,000 members and represents over 1,600 anticoagulation programs.

The AC Forum has been an advocate for improved anticoagulation care through the establishment of anticoagulation clinics, the hosting of web-based education sessions, and the development of clinical guidelines. In addition, the AC Forum has served the interest of patients taking anticoagulants by promoting increased availability of self-monitoring, and by advocating for appropriate reimbursement from third-party payers. Many members of the AC Forum are actively engaged in clinical trials testing new and exciting antithrombotic drugs for the treatment of venous and arterial thromboembolism. These new drugs may have a major impact on the traditional responsibilities of anticoagulation clinics, as highlighted by presentations at this year's conference.

David A. Garcia, Guest Editor.

D. A. Garcia $(\bowtie)$

Anticoagulation Clinic, University of New Mexico Health

Sciences Center, 1 University of New Mexico, MSC 074025,

Albuquerque, NM 87131, USA

e-mail: DAVGarcia@salud.unm.edu 